\title{
RELATIONSHIP BETWEEN SECONDARY STUDENTS' CRITICAL THINKING AND ACADEMIC ACHIEVEMENT: A CASE OF PUBLIC SCHOOLS
}

\author{
Muhammad Zafar Iqbal ${ }^{1}$, Muhammad Jamal Khan ${ }^{2}$, Tariq Javed ${ }^{3 *}$, Uzma Rao $^{4}$, Jahan Ara Shams ${ }^{5}$ \\ ${ }^{1}$ Lecturer Allama Iqbal Open University Islamabad, Pakistan; ${ }^{2}$ MPhil Scholar, Allama Iqbal Open University Islamabad, \\ Pakistan; ${ }^{3 *}$ Lecturer Allama Iqbal Open University Islamabad, Pakistan; ${ }^{4}$ Deputy District Education Officer (WEE) \\ Shahpur Sargodha, Pakistan; ${ }^{5}$ Assistant Professor, Punjab Higher Education Department, Pakistan. \\ Email: "tariq.benai@ aiou.edu.pk
}

Article History: Received on $14^{\text {th }}$ June 2021, Revised on $21^{\text {st }}$ June 2021, Published on $24^{\text {th }}$ June 2021

\begin{abstract}
Purpose of the Study: The purpose of this research study was to study the relationship between critical thinking (CT) and academic achievement among secondary school students in a district of Gilgit-Baltistan.

Methodology: Correlation design was applied to study the relationship between critical thinking and academic achievement. A sample of 400 students was selected through a convenient sampling technique to collect the data. Critical thinking was measured by applying an adapted tool (Sarigoz, 2012) and students' scores in annual examinations were taken as academic achievement (York, Gibson \& Rankin, 2015). Descriptive and inferential statistics were used to analyze the data.
\end{abstract}

Main Findings: Findings of the study revealed that female students, rural school students, and science group students showed slightly higher critical thinking than male, urban, and arts group students. A markedly low positive relationship was found between critical thinking and academic achievement. The results were consistent with earlier studies having a positive relationship between these variables. There were also low and markedly low relationships found between constructs of critical thinking and academic achievement. Some results of this study were inconsistent with the earlier research based on the context of the students. The study revealed that there is a discrepancy in aligning critical thinking with academic achievement.

Application of this study: The findings of the study help understand the relationship between critical thinking and academic achievement at the secondary level. It will surely assist the teachers in designing their classroom activities and modifications in teaching methodologies. It will boost the teachers to enhance the critical thinking of secondary school students.

Novelty/Originality of this study: The study is original as not a single research study determined the relationship between critical thinking and academic achievement of secondary school students in the region of district Ghizar in Gilgit-Baltistan.

Keywords: Critical Thinking, Deduction, Interpretation, Gilgit-Baltistan, Academic Achievement, Secondary School.

\section{INTRODUCTION}

The tendency toward carrying out multiple tasks at a time has become the demand in the current information age to manage various activities of daily life. The busy routines require internalizing information from the environment to make it knowledge by making one's meaning out of that information. Resolving complexities, framing interpretations, calculating possibilities, and making meaningful decisions need careful and effective thinking for valid and synthetic results in certain emerging situations. To control over distinct prejudices in such situations, Halpern (2014) suggested critical thinking to be employed for long a lasting impact. The ideas related to critical thinking in education were introduced by John Dewey when he wrote his book "How We Think" dates back to 1910 in which he discussed cognitive skills namely reasoning, logic, and judgment as important components of critical thinking (Dilley, Kaufman, Kennedy \& Plucker, 2015). Later on, in 1956, higher-order thinking abilities namely application, analysis, synthesis, and evaluation were included in critical thinking. These levels of thinking were used by educators as models for critical thinking (O'Riordan, Millard \& Schulz, 2020). In the first decade of the $21^{\text {st }}$ century, the language for levels of thinking was changed and named as cognitive processes such as applying, analyzing, evaluating, and creating (Dilley, et al, 2015: Yousufi \& Mohammadi, 2016). Historically, in the South Asian context, critical thinking in the form of questioning, discussion and debate has been linked with effect emphasizing fearlessness, kindness, and the essence of love. Reasoning had been given less importance. This approach led to discouraging those who ask critical questions and challenge the ideas of those who are in power and authority, were declared as people with undesirable behaviors. Consequently, two problems prevailed namely rote memorization and the dogmatic and non-pluralistic understanding of phenomena within the surrounding. In such a situation, Sellars, Fakirmohammad, Bui, Fishetti, Niyozov, Reynolds, Thapliyal, Smith, and Ali (2018) stated that critical thinking persisted only because of the non-orthodox interpretations of the existing beliefs, actions, costumes, traditions as well as other related practices. Promoting thinking minds has been a goal in the Pakistani context which means the people having critical thinking based on research-oriented activities and practices (Planning Commission of Pakistan, 2007). These activities include tasks that require well-organized 
intellectual, active, and skillful conceptualization, application, and analyzing exercises followed by synthesizing and evaluation of data gathered through observation, experience, reflection, and dialogues based on reasoning. In this regard, students needed to be facilitated through providing learning opportunities that would develop critical thinking among the students. Currently, critical thinking is assumed to be developed among the students through an embedded model of teaching critical thinking because of not proper training for teachers to teach critical thinking exclusively (Nauman, 2017). Thus, students can be benefitted from acquiring critical thinking by asking probing questions, encouraging them to express their ideas based on logical and evidence-based arguments. In teaching and learning, critical thinking plays an important role in maximizing students' academic achievements. Allowing students to take part in discussions, posing questions to the students, providing opportunities for students to solve problems, providing them exposures to interact with learning materials such as reading books in libraries, working in science and computer laboratories may help develop critical thinking among the students. Resultantly, students may excel in their academic achievement by applying their developed critical thinking. Academic achievement is attainments of learning objectives, acquisition of knowledge, skills and competencies, satisfaction, and improved performance (York et al., 2015). The findings of research studies on the relationship between critical thinking and academic achievement are varied. In their study, Akbarilakeh, Naderi, and Azizollah (2018) found a positive relationship between critical thinking and academic achievements. Another study revealed a positive but weak relationship between critical thinking and academic achievement (Fuad, Zubaidah, Mahanal \& Suarsini, 2017). There was a varying relationship found across the different construct of critical thinking (Kanbay, Islk, Aslan, Tektas and Kilic, 2017). Similarly, variation in the relationship of critical thinking and academic achievement were revealed in terms of gender and streams of study (Hassan \& Madhum, 2007). Thus, these studies leave the space open to conduct studies regarding the relationship between critical thinking and academic achievements.

This study was carried out to achieve the following objectives

1. To determine the relationship between students' critical thinking and academic achievement

2. To find the relationship between students' analysis of assumption and academic achievement.

3. To investigate the relationship between students' interpretation and academic achievement.

4. To find the relationship between students' inference and academic achievement.

5. To determine the relationship between students' deduction and academic achievement.

6. To find the relationship between students' evaluation of arguments and academic achievement.

The varying findings of previously conducted research studies on the relationship between critical thinking and academic achievement left gaps. This study was conducted to fill the gaps by measuring critical thinking and investigating the relationship between critical thinking and academic achievement of public sector secondary school students in Gilgit Baltistan. This relationship needs to be determined to add to the existing literature in the context of Gilgit Baltistan.

\section{LITERATURE REVIEW}

Locating, identifying, and synthesizing key information from relevant literature related to the topic is the most important segment in research studies. To review literature about critical thinking and academic achievement, online sources namely Educational Resources Information Center (ERIC), JSTOR, SAGE publications; Research Gate, and Google Scholar were searched for having a strong conception of the problem being studied. Critical thinking is a well-arranged and systematic way of thinking leading towards analysis to solve emerging problems. Before analyzing and solving problems, one must have some knowledge of the relevant concepts or facts related to that particular problem. It will help to understand the situation to proceed towards the processes of application, analysis, and evaluation to solve the problem. Critical thinking is the application of the cognitive abilities of a person to achieve intended results. Thus, it is a purposeful and goal-directed mental process that is rooted in Dewey and Halpern's theories (Helpern, 2014). A good critical thinker must have the ability to think in multiple dimensions such as cognitive skills and dispositions through deliberate, reflective, and logical thought in many situations. The sub-concepts of critical thinking include interpretation, analysis, inference, deduction, and evaluation according to various definitions, models and theories evolved from Dewey's work on critical thinking "how we think" in 1910 (Dilley, Kaufman, Kennedy \& Plucker, 2015). Critical thinking is the application of skills and tactics to make sure the achievement of intended outcomes. It is focused, rational, and goal-driven thinking used to effectively solve problems, make inferences and make meaningful decisions in a certain situation (Halpern, 2014).

The skill to analyze assumptions deals with some degree of basic clarifications of different types. Assumptions made can be analyzed seeking presuppositions required for propositions to make sense of the phenomena. The reasoning is needed but not logically necessary for making strong assumptions. With the help of hypothesis-testing procedures, assumptions used are judged. While analyzing assumptions, consideration is based on reasons from premises, factors, positions, and propositions within disagreement or doubt with their thinking (Halpern, 2014). Interpretation involves skills to make one's viewpoint and justify them after incorporating dispositions and abilities is termed as interpretation. It includes the ability to smoothly proceed according to the situation followed by a conclusion. Keeping own thinking in observation through any sort of mental exercise utilizing feelings, knowledge, and experiences of others $f$ into the interpretation. 
Employing sequential techniques in printed and verbal communication is the ability of critical thinking (Ennis, 2011). Apart from analyzing assumptions and interpretation, making an inference is another skill of critical thinking. From a sample of statistical data, inferences can be made in the form of generalizations. Furthermore, inferences can also be made from explanatory hypotheses including conclusions, specific and general causal claims as well as interpretations of its' intended meanings. The activities related to inference include designing small tests, seeking evidence and counterevidence, seeking other possible explanations. According to Zivkovica (2016), criteria for making inferences involve; the inference needs to explain the evidence, consistent with all known facts, competent sincere effort to find supporting and opposing data and the inference needs to seem plausible, simple, fitting into a larger view. Another skill of critical thinking is making deductions from the subject matter of any verbal communication. Using the class and conditional logic, logical terminology, negation and double negation, necessary and sufficient language, people make deductions (Halpern, 2014). The skill to evaluate arguments is an important element of critical thinking. It includes the ability to identify conclusions, single out reasons, analyze and highlight worthlessness, and look for structure in an argument followed by summarising arguments (Zivkovica, 2016). Asking for clarifications and challenge arguments demonstrating agreement/disagreements are indicators of evaluating arguments. While evaluating arguments, Halpern (2014) believes that it should expose the positive and negative features revealing a productive reflection on the matter. The unrevealed assumptions in arguments can be realized when there is a deliberate effort through considering the validity of the information source leading towards deciding the best possible way.

Efforts made by policymakers, educators, teachers, and parents in school settings aimed at improving the academic achievement of students to prospect a productive society in the future. An academic achievement which is also called an academic success by some educationists is defined as the outcomes of students going through a variety of teaching and learning programs. Academic achievement is defined as the benefits a student obtains from the teaching and learning activities. It also includes the level of knowledge, skills, experiences, and attitudes that have been intended to be imparted to the students in school settings through different subject areas. According to Okasha (2021), critical thinking techniques in academic areas include debates, problem-solving, self, and peer assessment. Critical dialogue means the discussion organized following rules of logic (Letseka \& Zireva 2013). The students display critical thinking through participating in dialogues in a classroom (Liang \& Fung, 2021). The measurement of academic achievement is carried out usually in the form of test scores (Bhat, 2013). Academic achievement in the eastern context is thought of as the key element to evaluate the individuals' potentials and abilities. The reason behind this thinking is because the contributing factors towards academic achievement are study habits, mental abilities, and attitudes towards academic and social environment.

Factors affecting academic achievement include learning styles, personality traits, incremental intelligence, self-efficacy, learning strategies, motivation, and technology (Bhat, 2013). Research studies reveal that the learning styles of the students leave a significant impact on the academic achievement of the students. Positive relationships have been observed between personality traits and academic achievement among secondary school students. Intelligence has been a significant predictor of academic success. It has deep roots in the family background as inheritance and environment affect intelligence. The socio-economic status of the parents contributes significantly towards the academic achievement of the students (Sirin, 2005). Although, there are some tools designed to measure critical thinking such as Cornell Critical Thinking Test (Sumarni, Supardi \& Widiarti, 2018)., Watson Glaser Critical Thinking Appraisal, California Critical Thinking Skills Test, Ennis-Weir Critical Thinking Essay Test, and Halpern Critical Thinking Assessment (Samar \& Basiroo, 2016). According to Hasinger (2020), these tests are conducted to predict the future potentials of the students as well as for placement purposes. There are validity issues with these tools because of the vague, imprecise, confusing, and covert instructions. In case of inaccurate scoring its validity further is lessen (Possin, 2014). However, a tool was prepared and applied by Sarigoz (2012) to measure the critical thinking skills of high school students. The tool was designed in such a way that it measures the constructs measured in the above-mentioned tools for measuring critical thinking. Each statement to be measured has a five-point scale from 0 to 4 denoting never to always $(0=$ never, $1=$ rarely, $2=$ sometimes, $3=$ often, 4=always). The statements were based on analyzing assumptions, interpretation, making inferences, deduction, and evaluation of arguments. Scoring or interpretation is done on a general arithmetic average for each point in the scale.

\section{Relationship between Critical Thinking and Academic Achievement}

Various research studies have different findings regarding the relationship between critical thinking and the academic achievement of students in different institutions. According to Akbarilakeh, Naderi, and Azizollah (2018), there is a positive significant relationship between critical thinking and academic achievements. In their study, they found that the students who had higher levels of critical thinking performed better than the students who had an average level of critical thinking and the students with an average level of critical thinking showed better performance than the students with lower levels of critical thinking skills.

Thalib, Corebima, and Ghofur (2017) carried out a study on students with a high and low level of academic success and found a negative relationship between critical thinking and academic achievements. Shaw, et al (2020) found a very high correlation between scores in entrance exams and critical thinking. Some studies compared the levels of critical thinking between male and female students and their achievement in academic tasks. In such a study, differing levels of critical thinking skills in different areas of academic tasks were found between male and female students (Fuad, et al, 2017). A 
study conducted by Hassan and Madhum (2007) found a significant variation between levels of critical thinking between students of different streams of study. Another study revealed that higher-order thinking skills such as analysis, comparison, and evaluation had a significant relationship with the academic performance of male students. However, the higher-order thinking skill namely inference had no significant relationship with the performance of male students. On the other hand, the higher-order thinking skills such as analysis, inference, and evaluation had a significant relationship with the academic performance of female students. However, in female students, comparison skills had no significant relationship with the performance of female students (Ramos, Dolipas \& Villamor, 2013). In their research study to find out the relationship between critical thinking skills and academic achievement, Kanbay, et al (2017) found a positive but low level of relationship between critical thinking skills and academic achievements. There was no significant statistical variance found between male and female students. In the same study, they found a higher level of critical thinking skills of the urban students than the rural students. The levels of critical thinking skills were the same when compared in terms of gender, parental educational status, and economic background of the family.

The following hypotheses were designed to be tested in this research study

$\mathbf{H}_{01}$ : There is no significant relationship between students' critical thinking and academic achievement.

$\mathbf{H}_{\mathbf{0 2}}$ : There is no significant relationship between students' analysis of assumptions and academic achievement.

$\mathbf{H}_{\mathbf{0 3}}$ : There is no significant relationship between students' interpretation and academic achievement.

$\mathbf{H}_{04}$ : There is no significant relationship between students' inference and academic achievement.

$\mathbf{H}_{05}$ : There is no significant relationship between students' deduction and academic achievement.

$\mathbf{H}_{\mathbf{0 6}}$ : There is no significant relationship between students' evaluation of arguments and academic achievement.

\section{METHODOLOGY}

To find out the relationship between critical thinking and academic achievement among the students of public sector secondary schools, a co-relational research design of a quantitative approach was applied. The overall population in this study was public sector secondary school students of grade ten in district Ghizar. However, being the population in a vast and scattered area, the accessible population was tenth-grade students in sub-division Punial-Ishkoman which was the representative of the other two sub-divisions of district Ghizar. There is the same curriculum implemented at the secondary level throughout public sector schools in district Ghizar. Best and Kahn (2006) shared that, due to the population being huge numbered, and scattered, it needed to select a representative of the whole population so that the findings of the research are appropriately generalized. At the secondary level, there are two streams of study which go side by side namely science and arts groups in public sector secondary schools. Therefore, male and female students of both streams were taken as the population in this study. Applying a convenient sampling technique, a sample of 400 which became $32 \%$ of the whole population was selected from the whole population to save time and make the procedure of data collection simple. In this study, it was difficult to collect data from 400 selected samples due to COVID-19. Thus, out of 400 selected samples, two hundred and forty-four (244) students responded by filling the questionnaire because which becomes a $61 \%$ response rate. The instrument used in this study to measure critical thinking skills was the adapted questionnaire to measure critical thinking (Sarigoz, 2012) of secondary school students. Cui, Zhu, Qu, Tie, Wang, and Qu (2021) applied co-relational design and questionnaires in their study to assess the critical thinking dispositions of students. On the other hand, the academic achievement of the students was measured by their scores in annual examination results (Bhat, 2013; York et al., 2015). In correlation studies, records such as grade transcripts can be used for one set of quantitative data, and the collection of another set of quantitative data some sort of instrument such as tests, a questionnaire can be considered (Fraenkel, Wallen \& Hyun, 2012). Therefore, the questionnaire was used as the tool to measure critical thinking and graded transcripts of the students were used to collect data regarding academic achievements. The adapted questionnaire as a data collection tool was used in this study translated into the Urdu language from English because usually in public sector schools, students are not good enough in English because of the bilingual medium of instruction. The adapted tool was validated by two bilingual experts and two experts in the Urdu language to ensure validity and for content validity, the tool was reviewed by experts in the critical thinking and research process. The initial draft of the tool was modified based on feedback given by experts where changes were made in terms of language structure and terminology in Urdu.

Table 1: Alpha reliability coefficient of CT before item deletion ( $\mathrm{N}=40)$

\begin{tabular}{lll}
\hline Scale & Cronbach's Alpha & Number of items \\
\hline Critical Thinking & .824 & 25 \\
\hline
\end{tabular}

The tool was then pilot tested with forty students of public sector secondary schools. Using SPSS, the reliability of twenty-five items was found 0.824 through Cronbach's alpha which is very high as 1 . Nursa'Adah, Sari, and Affifah (2021) said high to the Cronbach's value of 0.65. As it is across constructs of critical thinking such as analysis of assumptions, inference, deduction, interpretation, and evaluation of arguments which were found respectively 0.520, $0.509,0.590,0.672$, and 0.546 for five items each. There were two types of data collected in this study such as levels of 
critical thinking skills and academic achievements. A tool for measuring the critical thinking of high school students (Sarigoz, 2012) was adapted to collect data about critical thinking. It was the start of COVID-19, the instrument was being developed. In the first week of December 2019, the proposal was approved for this research study to be carried out. It took two months (December 2019 and January 2020) to develop, pilot, and validate the tool. Meanwhile, the Coronavirus had started to be spreading. In February, data collection was started in this study, and on collecting data from more than 200 sample schools were closed in March 2020. Still, 35 to 40 sample was accessed going door to door because the technique was convenient for selection of sample. This way data collected from 244 students out of 400 hundred planned samples.

\section{DATA ANALYSIS}

While analyzing data collected from 244 respondents, it was found that 127 out of 244 respondents had cleared their annual examination. 117 students had supplementary in their annual examination results. Therefore, their academic achievement could not be measured and they were excluded from the analysis. Statistical tests for data analysis were applied to 127 respondents. Pearson correlation coefficient was calculated to study the relationship between critical thinking and academic achievement of public sector secondary school students.

\section{RESULTS}

Hypothesis $\left(\mathrm{H}_{01}\right)$ There is no significant relationship between students' critical thinking and academic achievement.

The mean score on critical thinking was found 2.6 on a scale of $0-4(0-2=10 \mathrm{w}, 2-3=$ medium, and $3-4=$ high $)$, and the mean score in academic achievement among respondents was found 58\%. Table 2 reveals that the Pearson correlation coefficient between critical thinking and academic achievement was found markedly low and negligibly positive and statistically significant $(\mathrm{r}=.055, \mathrm{p}<.05)$.

Table 2: Correlation between critical thinking and academic achievement

\begin{tabular}{ccc}
\hline $\mathbf{N}$ & $\mathbf{R}$ & $\mathbf{P}$ \\
\hline 127 & .055 & .54 \\
\hline
\end{tabular}

Hypothesis $\left(\mathrm{H}_{02}\right)$ There is no significant relationship between students' analysis of assumptions and academic achievement.

Table 3 reveals that the mean score in the analysis of assumptions is 2.4 on a scale of 0 having no analysis to 4 having the high analysis of assumptions. Thus, the mean (2.4) falls around the medium level of critical thinking. The means score in academic achievement among respondents is 58\%. The Pearson correlation coefficient between analysis of assumptions and academic achievement was found .005 which is markedly low and negligibly positive at $\mathrm{p}=.96$.

Table 3: Correlation between analysis of assumptions and academic achievement

\begin{tabular}{ccc}
\hline $\mathbf{N}$ & $\mathbf{r}$ & $\mathbf{P}$ \\
\hline 127 & .005 & .96 \\
\hline
\end{tabular}

Hypothesis $\left(\mathrm{H}_{03}\right)$ There is no significant relationship between students' interpretation and academic achievement.

Regarding the relationship between interpretation and academic achievement among 127 respondents, the Pearson product-moment correlation coefficient was calculated which was found 0.2 at a significance level 0.026 . The mean score on interpretation was found 2.7 which reveals the approaching high level of interpretation. It reveals a very low positive relationship between interpretation and academic achievement of secondary school students.

Table 4: Relationship between interpretation and academic achievement

\begin{tabular}{ccc}
\hline $\mathbf{N}$ & $\mathbf{r}$ & $\mathbf{P}$ \\
\hline 127 & .20 & .026 \\
\hline
\end{tabular}

Hypothesis $\left(\mathrm{H}_{04}\right)$ There is no significant relationship between students' inference and academic achievement.

There is a markedly low and negligible correlation between making inferences and academic achievement revealed by table 4.7. The correlation coefficient was calculated as 0.026 at a significant level of 0.775 .

Table 5: Correlation between making inference and academic achievement

\begin{tabular}{ccc}
\hline $\mathbf{N}$ & $\mathbf{r}$ & $\mathbf{P}$ \\
\hline 127 & .026 & .775 \\
\hline
\end{tabular}

The means score of 127 students in making inference was found 2.6 which stands at the medium level on a scale of 0-4 (low-high). Thus, the null hypothesis is not rejected at this level as there is no significant relationship between making inferences and the academic achievement of secondary school students. 


\section{Hypothesis $\left(\mathrm{H}_{05}\right)$ There is no significant relationship between students' deduction and academic achievement.}

Calculation of Pearson product-moment correlation coefficient revealed that a markedly low and negligible negative correlation was found between deduction and academic achievement among secondary school students. Table 4.8 shows that the Pearson correlation is 0.013 at a significance of 0.88 . The means score in a deduction at 2.8 on a scale from 0 to 4 (low to high) shows that students are touching a high level in the deduction. Based on this result, it is observed that there is no significant relationship between deduction and academic achievement. Thus, the null hypothesis is not rejected here rather accepted.

Table 6: Correlation between deduction and academic achievement

\begin{tabular}{ccc}
\hline $\mathbf{N}$ & $\mathbf{r}$ & $\mathbf{P}$ \\
\hline 127 & .013 & .88 \\
\hline
\end{tabular}

Hypothesis $\left(\mathrm{H}_{06}\right)$ There is no significant relationship between students' evaluation of arguments and academic achievement.

While analyzing data on the relationship between the evaluation of arguments and academic achievement through applying Pearson product-moment, the correlation coefficient was found 0.027 at $\mathrm{p}=.767$ which meant that there is a markedly low and negligible positive correlation between the valuation of arguments and academic achievement. The mean score of students on evaluation of arguments was calculated as 2.5. Table 4.9 reveals the detail of means, correlation coefficient, and significance regarding the relationship between evaluating arguments and academic achievement.

Table 7: Relationship between the evaluation of arguments and academic achievement

\begin{tabular}{ccc}
\hline $\mathbf{N}$ & $\mathbf{r}$ & $\mathbf{P}$ \\
\hline 127 & .027 & .767 \\
\hline
\end{tabular}

\section{FINDINGS}

Critical thinking as defined in this research study is an ability that students use to overcome/solve the problems encountered in their daily life particularly in academic areas. There are five constructs of critical thinking namely, analysis of assumptions, interpretation, making inference, deduction, and evaluation of arguments. The data about critical thinking among the students was collected on a five-point scale 0-4 (low-high). After collecting data, for analysis of data, scores obtained from five-point scales were converted into three categories as high, moderate, and low where high was quantified as 3 , medium to 2 , and low to 1 . The calculation of mean revealed that in critical thinking female students' mean score was slightly higher than the means of male students.

Academic achievement is the acquired knowledge and understanding about certain concepts in the subject areas and academic skills by students as a result of participation in teaching and learning activities. The data about academic achievement was taken from the cumulative scores obtained by the students in their annual board examinations. Annual scores were converted into percentages and used in data analysis. After collection of data, it was found that 117 students out of 244 students had not cleared their results in annual examination because of supplementary in different subjects. Therefore, they were excluded from the analysis.

To investigate the relationship between critical thinking and academic achievement of public sector secondary school students, the Pearson correlation coefficient was calculated. It can be found that in critical thinking, the mean is higher and the standard deviation is less. On the other hand, the standard deviation is higher in academic achievement. It means that the students have higher critical thinking levels and less academic achievement in public sector secondary schools. Therefore, there is a markedly low and negligible positive and statistically significant correlation between critical thinking and academic achievements.

Analysis of data regarding the relationship between analysis of assumptions as one of the constructs of critical thinking and academic achievement showed that the mean score in the analysis of assumption is on more above average. Then while analyzing values from 0-1 were considered low, 2-3 as a medium, and 3-4 were considered as high critical thinking. Thus, the mean falls around a medium level of critical thinking. The means score in academic achievement among respondents was fifty-eight people. The Pearson correlation coefficient between analysis of assumptions and academic achievement revealed a markedly low and negligible positive relationship. Analysis of assumption generally is a skill that most needs to be practiced in English and mathematics. The markedly low relationship with academic achievement reveals that in public sector secondary schools' classrooms skill of analysis is not focused.

While analyzing data about the relationship between interpretation and academic achievement, the Pearson productmoment correlation coefficient was calculated at the significance level 0.026. The mean score on the interpretation of the students was approaching a high level in interpretation. A low positive relationship was found between interpretation and academic achievement of secondary school students. Being a predictor of academic achievement, the skill of interpretation was expected to have a high relationship. 
The data were analyzed by using the Person correlation coefficient to find the relationship between inference and academic achievement. The means score of students in making inference stands at the medium level on a scale of 0-4 (low-high). Pearson correlation coefficient depicted that there is a markedly low and negligible correlation between making inferences and academic achievement.

Analysis of data applying Pearson correlation coefficient to find out the relationship between deduction and academic achievement revealed a markedly low and negligible correlation. It was found that students are touching a high level in the deduction. However, there was no significant relationship between deduction and academic achievement.

Applying Pearson $r$, the relationship between the evaluation of arguments and academic achievement was studied. Findings of the Pearson product-moment resulted that there is a markedly low and negligible positive correlation between the valuation of arguments and academic achievement. The mean score on evaluation of arguments was calculated stands at medium level critical thinking among the secondary school students.

\section{DISCUSSION}

This research study investigated the relationship between critical thinking and the academic achievement of secondary school students. Through a questionnaire, critical thinking was measured while the cumulative scores of the annual board examination were taken as academic achievements. Critical thinking was articulated as high, medium, and low were used in this study. Likewise, academic achievement in the form of examination scores (York et al., 2015) is expressed in grades or percentages.

Analysis of the data revealed that there is a markedly low positive correlation between critical thinking and academic achievement of secondary school students. This result is consistent with a research study carried out by Kanbay, et al (2017) who found a positive but low level of relationship between critical thinking skills and academic achievements. The finding of a positive relationship is also consistent with the results of the research study conducted by $\underline{\text { Akbarilakeh, }}$ Naderi, and Azizollah (2018) that there was a positive significant relationship between critical thinking and academic achievements. However, here the finding is a low positive relationship instead of a significant relationship. On the other hand, Thalib et al., (2017) had opposite results while comparing students with a high and low level of academic success and found a negative relationship between critical thinking and academic achievements.

A study revealed that inference had no significant relationship with the performance of male students and, analysis and evaluation had a significant relationship with the academic performance of female students (Ramos, et al, 2013). The results of this study were inconsistent as there is there was a low positive relationship found between inference and academic achievement. Also, there is no significant relationship between analysis of assumptions and evaluation with academic achievement found in this study. In addition to it, this study showed that female students have a higher level in analysis of assumption and evaluation of arguments leading towards high academic achievements. In the same study, they found a higher level of critical thinking skills of the urban students than the rural students. Conversely, the results of this study are inconsistent as urban school students and rural school students are at the same level regarding critical thinking.

\section{CONCLUSIONS}

This research study revealed a low positive relationship between critical thinking and academic achievement among public sector secondary school students. Critical thinking involved analysis of assumptions, interpretation, inference, deduction, and evaluation of arguments. The gender difference was the same as shown by many of the researchers that females have a high level of critical thinking as compared to the male students. The positive relationship between critical thinking and academic achievement can be enhanced from low to moderate and high relationships by putting efforts to develop both critical thinking and academic achievement in secondary schools. In classrooms, if activities to develop critical thinking are incorporated in teaching and learning, then academic achievement can be enhanced. According to Helpern (2014), teachers can achieve what they expect from the students when they explicitly teach critical thinking in classrooms. In this regard, critical thinking skills such as analysis of assumptions, interpretation, inference, deduction, and evaluation of argumentation if are given space in curricular areas they lead towards maximized academic achievement among secondary schools' students. Assessment of students' academic achievement needs to be revisited whether the element of critical thinking is visibly reflected or lacking. Efforts to align critical thinking and academic achievement in the teaching and learning process can provide desired results.

\section{LIMITATION AND STUDY FORWARD}

The current study is not without limitations. Correlations studies to be more effective need a larger number of samples. This study was in the stage of data collection from a district of Gilgit-Baltistan when COVID-19 was initially spreading. Therefore, data collection could be collected from 244 students out of 400 students. Thus, the response rate in this regard stayed at $61 \%$. We encourage the researchers to take a larger sample and utilize more sophisticated statistical methods for future research and extend this research to other regions of Pakistan. 


\section{RECOMMENDATIONS}

Based on findings and discussion of this research study, the following recommendations are made;

- This study showed a low level of the positive relationship between critical thinking and academic achievement among public sector secondary school students. It is recommended that critical thinking needs to be developed among the students and particular focus needs to be paid to male and arts group students.

- Critical thinking and academic achievement are recommended to be aligned in teaching and learning on a priority basis so that they will supplement each other.

- The sub-constructs of critical thinking such as analysis, interpretation, inference, deduction, and argumentation need to be developed among the students so that they would apply them to maximize their academic achievements.

- This study was conducted to find the relationship between critical thinking and academic achievement in the form of cumulative scores of annual examinations. It is recommended similar study can be carried out to find the relationship between critical thinking and scores in any subject area.

- Due to coronavirus disease-2019 (COVID-19), this research study was conducted for 244 samples. It is also recommended that in the future, researchers may work with a large sample in this area.

\section{ACKNOWLEDGEMENT}

The present research was conducted without taking any kind of financial help from institutions.

\section{AUTHORS CONTRIBUTION}

Muhammad Zafar Iqbal has contributed in research conceptualization, acquisition, and data analysis and Muhammad Jamal Khan finalized the introduction, research tools and collected the data. Tariq Javed assisted in completing literature review while Uzma Rao wrote conclusions and recommendations and formatting of the document. Jahan Ara Shams done proof reading, finalized the citations and references.

\section{REFERENCES}

1. Nursa'adah, E., Sari, D., \& Affifah, I. (2021). Domain-specific critical thinking skills: Designing and analysis the instrument test on thermochemistry. In Journal of Physics: Conference Series, 1731(1), 012025. IOP Publishing. https://doi.org/10.1088/1742-6596/1731/1/012025

2. Akbarilakeh, M., Naderi, A., \& Azizollah, A. (2018). Critical Thinking and Emotional Intelligence Skills and Relationship with Students' Academic Achievement. Prensa Med Argent. https://doi.org/10.4172/0032745X.1000280

3. Best, J. W., \& Kahn, J. V. (2006). Research in Education (10th ed.). Boston: Pearson

4. Bhat, M. H. (2013). Academic achievement of secondary school students in relation to self-concept and parental encouragement. International Journal of Recent Scientific Research, 4(6), 738- 741.

5. Cui, L., Zhu, Y., Qu, J., Tie, L., Wang, Z., \& Qu, B. (2021). Psychometric properties of the critical thinking disposition assessment test amongst medical students in China: a cross-sectional study. BMC Medical Educatio, 21(10), 01-08. https://doi.org/10.1186/s12909-020-02437-2

6. Dilley, A., Kaufman, J. C., Kennedy, C., \& Plucker, J. A. (2015). Without we know about critical thinking: 4 Cs research series. Retrieved September 19, 2019, from https://www.csai-online.org/resources/withat-we-knowabout-critical-thinking-4cs-research-series

7. Ennis, R. (2011). Critical thinking: Reflection and perspective Part II. Inquiry: Critical thinking across the Disciplines, 26(2), 5-19. https://doi.org/10.5840/inquiryctnews201126215

8. Fraenkel, J. R., Wallen, N. E., \& Hyun, H. H. (2012). How to design and evaluate research in education (8th ed.). New York: McGraw-Hill

9. Fuad, N. M., Zubaidah, S., Mahanal, S., \& Suarsini, E. (2017). Improving junior high schools' critical thinking skills based on test three different models of learning. International Journal of Instruction, 10(1), 101-116. https://doi.org/10.12973/iji.2017.1017a

10. Halpern, D. F. (2014). Halpern Critical Thinking Assessment. Austria: Schuhfried Retrieved November 14, 2019, from https://drive.google.com/file/d/0BzUoP_pmwy1gdEpCR05PeW9qUzA/view

11. Hasinger, E. (2020). Cornell critical thinking test guide. Retrieved August 2020, from https://www.tests.com/ Cornell-Critical-Thinking-Testing

12. Hassan, K, E., \& Madhum, G. (2007). Validating Watson Glaser Critical Thinking Appraisal. Higher Education, 54, 361-383. https://doi.org/10.1007/s10734-006-9002-Z

13. Kanbay, Y., Islk, Aslan, O., Elif, I., \& Kilic, N. (2017). Problem solving and critical thinking skills of undergraduate nursing students. Journal of Higher Education and Science, 3(3), 244-254.

14. Letseka, M., \& Zireva, D. (2013). Obstacles to the development of critical thinking dispositions among the student teachers at Mongster Teachers' College, Zimbabwe. Mediterranean Journal of Social Sciences, 4(6), 671-680. 
15. Liang, W., \& Fung, D. (2021). Fostering Critical Thinking in English as a Second Lanauge Classrooms: Challenges and Opportunitie. Thinking Skills and Creativity, 39. https://doi.org/10.1016/j.tsc.2020.100769

16. Nauman, S. (2017). Lack of critical thinking skills leading to research crisis in developing countries: A case of Pakistan, Learned Publ, 30(3), 233-236. https://doi.org/10.1002/leap.1091

17. Okasha, M. A. H. (2021). The Effect of Critical Thinking Techniques for improving EFL Reading Skills. Journal of Research in Curriculum, In struction and Educational Technology, 7(1), 141-157. https://doi.org/10.21608/jrciet.2021.134639

18. O'Riordan T, Millard, D, E, \& Schulz, J. (2020). Is critical thinking happening? Testing content analysis schemes applied to MOOC discussion forums. Comput Appl Eng Educ, 1(20). https://doi.org/10.10 $02 /$ cae. 22314

19. Planning Commission Government of Pakistan. (2007). Pakistan in $21^{\text {st }}$ Century: Vision 2030. Retrieved December 01, 2019, from http://www.planningcommission.gov.pk

20. Possin, K. (2014). Critique of the Watson-Glaser Critical Thinking Appraisal Test: The more you know, the lower your score. Informal Logic, 34(4), 393-416. https://doi.org/10.22329/il.v34i4.4141

21. Ramos, J. L., \& Dolipas, B. B., \& Villamor, B. (2013). Higher order thinking skills and academic performance in physics of college students: A regression analysis. International journal of innovative interdisciplinary research, 4(10), 48-60.

22. Samar, R. G., \& Basiroo, S. R. (2016). Critical Thinking Assessment: Specifying The Contents Tipping the Balance in Favor of A Discipline-Specific Approach in EFL Learning Context. Modern Journal of Language Teaching Methods, 6(8), 51-61.

23. Sarigoz, O. (2012). Assessment of the high school students' critical thinking skills. Procedia: Social and Behavioral Science, 46, 5315 - 5319. https://doi.org/10.1016/j.sbspro.2012.06.430

24. Sellars, M., Fakirmohammad, R., Bui, L., Fishetti, J., Niyozov, S., Reynolds, R., \& Ali, N. (2018) Conversations on critical thinking: Can critical thinking find the way forward as the skill set and mindset of the century? Education Sciences, 8(4), 205. https://doi.org/10.3390/educsci8040205

25. Sirin, S, R. (2005). Socioeconomic Status and Academic Achievement: A Meta-Analytic Review of Research. Review of Educational Research, 75(3), 417-453. https://doi.org/10.3102/00346543075003417

26. Shaw, A., Liu, O. L., Gu, L., Kardonova, E., Chirikov, I., Li, G., ... \& Loyalka, P. (2020). Thinking critically about critical thinking: validating the Russian HEIghten ${ }^{\circledR}$ critical thinking assessment. Studies in Higher Education, 45(9), 1933-1948. https://doi.org/10.1080/03075079.2019.1672640

27. Sumarni, W., Sudarti, K. I., \& Widiarti, N. (2018). IOP Conf. Ser.: Mater. Sci. Eng. 349012066. https://doi.org/10.1088/1757-899X/349/1/012066

28. Thalib, M., Corebima, A. D., \& Ghofur, A. (2017). Comparison on Critical Thinking Skill and Cognitive Learning Outcome among Students of X Grade with High and Low Academic Ability through Reading Questioning Answering (RQA) Strategy. Journal of Science Education, 5(1), 26-31.

29. York, T. T., Gibson, C., \& Rankin, S. Defining and measuring academic success. Practical assessment, research and evaluation, 20(5).

30. Yousufi, S., \& Mohammadi, M. (2016). Critical thinking and reading comprehension among postgraduate students: The case of gender and language proficiency level. Journal of Language Teaching and Research, 7(4), 802-807. https://doi.org/10.17507/j1tr.0704.23

31. Zivkovica, S. (2016). A Model of Critical Thinking as an Important Attribute for Success in the 21st Century. Procedia - Social and Behavioral Sciences 232, 102 - 108. https://doi.org/10.1016/j.sbspro.2016.10.034 